\title{
Nanocomposite Thin Film of Poly(3-aminobenzoic acid) and Multiwalled Carbon Nanotubes Fabricated through an Electrochemical Method
}

\author{
Paphawadee Netsuwan, ${ }^{1}$ Wirat Chaisu, ${ }^{2}$ Sukon Phanichphant, ${ }^{3}$ and Saengrawee Sriwichai ${ }^{2}$ \\ ${ }^{1}$ Nanoscience and Nanotechnology Program, Graduate School, Chiang Mai University, Chiang Mai 50200, Thailand \\ ${ }^{2}$ Department of Chemistry, Faculty of Science, Chiang Mai University, Chiang Mai 50200, Thailand \\ ${ }^{3}$ Materials Science Research Center, Faculty of Science, Chiang Mai University, Chiang Mai 50200, Thailand \\ Correspondence should be addressed to Saengrawee Sriwichai; sriwichai473@yahoo.com
}

Received 27 February 2014; Revised 6 June 2014; Accepted 10 June 2014; Published 24 June 2014

Academic Editor: Amit Bandyopadhyay

Copyright (C) 2014 Paphawadee Netsuwan et al. This is an open access article distributed under the Creative Commons Attribution License, which permits unrestricted use, distribution, and reproduction in any medium, provided the original work is properly cited.

\begin{abstract}
The composite thin films of poly(3-aminobenzoic acid) (PABA) and multiwalled carbon nanotubes (MWNTs) are successfully fabricated through an electrochemical method. The composite mixtures containing $50 \mathrm{mM}$ of 3-aminobenzoic acid with various concentrations of MWNTs $(1.0,2.5,5.0,7.5$, and $10 \mathrm{mg} / \mathrm{mL})$ in $0.5 \mathrm{M} \mathrm{H}_{2} \mathrm{SO}_{4}$ were prepared and used in this study. Cyclic voltammetry $(\mathrm{CV})$ was used for fabrication and monitoring the electropolymerization of the composite thin films with potential range of 0 to $1100 \mathrm{mV}$ for 5 cycles at scan rate of $20 \mathrm{mV} / \mathrm{s}$ on indium tin oxide- (ITO)-coated glass substrate. UV-vis absorption spectroscopy, atomic force microscopy (AFM), and scanning electron microscopy (SEM) techniques were employed to characterize the obtained composite thin films. It was found that MWNTs can enhance the peak current of CV traces of the PABA/MWNTs composite thin films without affecting the UV-vis absorption spectra. The surface morphology of the thin films can be studied using AFM and SEM techniques.
\end{abstract}

\section{Introduction}

The application of the conducting polymers has attracted attention in various fields such as medical, industrial, and environmental fields [1-5]. Conducting polymers such as polypyrrole, polyaniline, polythiophene, and their derivatives can be obtained through both chemical and electrochemical polymerization. Their unique conjugated $\pi$-electron backbone system had led them to have unusual electronic properties such as electrical conductivity, low energy optical transitions, low ionization potential, and high electron affinity. Various conducting polymers have been widely used in sensor applications [5-10]. Among these conducting polymers, poly(aminobenzoic acid), which is one of polyaniline derivatives, is a conducting polymer containing electron-rich nitrogen atom and high electron density of carbonyl group. This makes it easily electropolymerized on the electrode [11, 12]. Carboxylated polyanilines with both ortho- and metasubstitutions known to show self-doping have been studied as a promising polyaniline derivative for biosensor applications. The carboxylic acid group serves as a functional group that can be used as a matrix material for immobilization onto substrates or for covalent bonds with biomolecules such as proteins and antibodies [13]. Recently, the ultrathin films of poly(3-aminobenzoic acid) (PABA) were fabricated by electropolymerization on gold-coated high-refractive index glass slide as working electrode to construct the surface plasmon resonance (SPR) immunosensor for detecting human immunoglobulin G [13]. The other poly(aminobenzoic acid), poly(o-aminobenzoic acid), was also electropolymerized on boron-doped diamond electrode by cyclic voltammetry for construction of the amperometric immunosensor [14].

Carbon nanotubes (CNTs) show many advantages such as small size, high electrical, thermal conductivity, high specific surface area, and long term chemical stability which can improve the electrochemical reactivity of biomolecules and promote the electron transfer of redox reaction in 


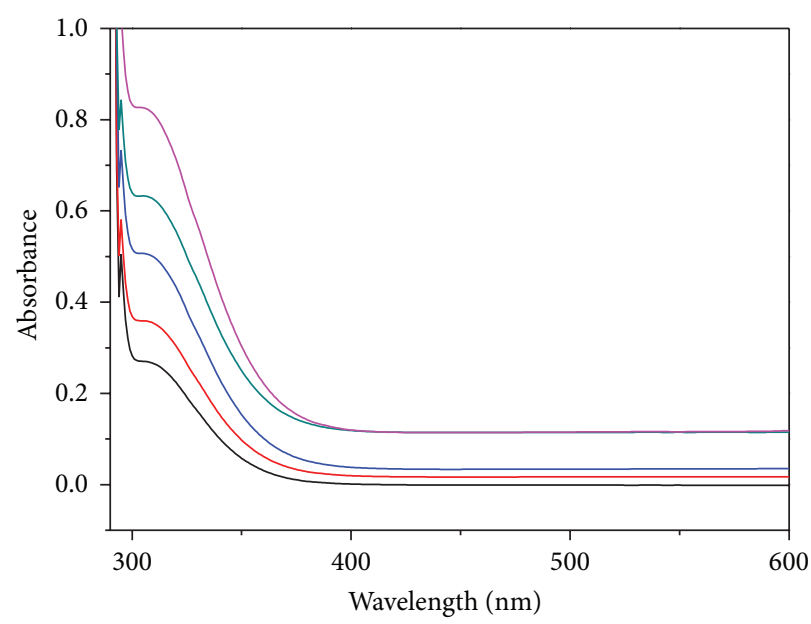

(a)

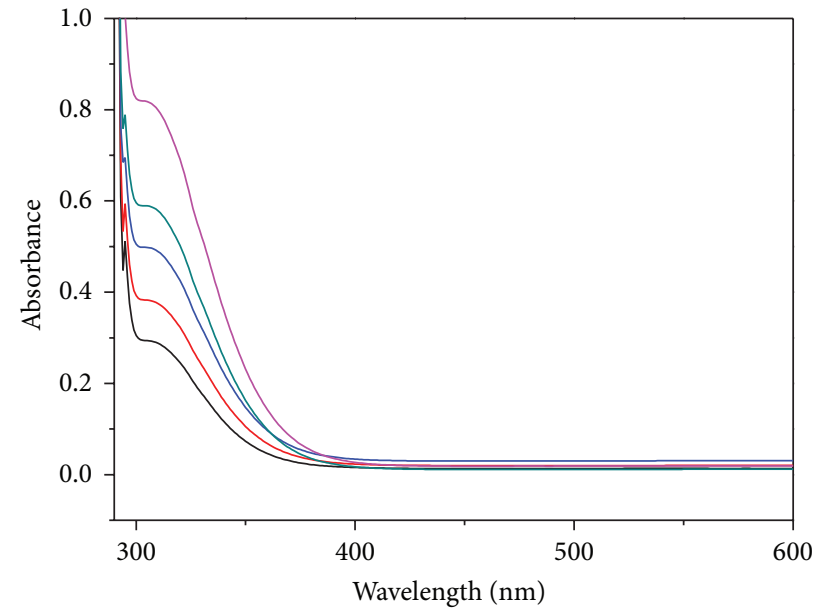

(b)

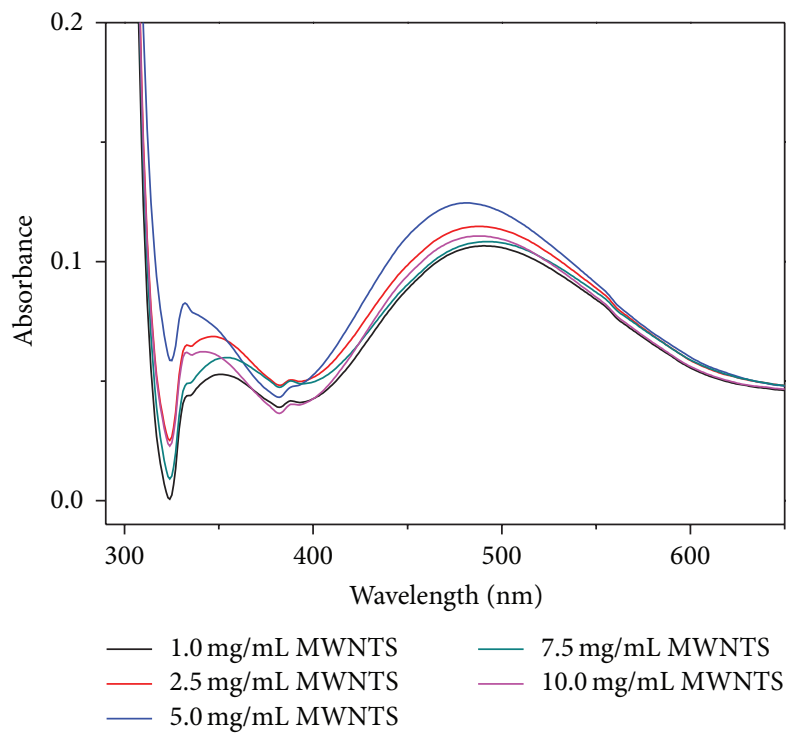

(c)

FIGURE 1: UV-vis spectra of (a) composite mixtures after sonication, (b) composite mixtures after sonication/centrifugation, and (c) composite thin films after electropolymerization for 5 cycles.

electropolymerization [15-20]. CNTs are hexagonal arrangements of carbon atoms which can be classified as singlewalled (SWNTs) and multiwalled (MWNTs) carbon nanotubes. Since MWNTs are easier to synthesize and are of lower price than SWNTs [16], MWNTs were chosen for preparing the composite mixture in this work. The film of poly(2,6-pyridindediamine)/MWNTs composite and gold nanoparticles was developed to be used as amperometric immunosensor for detecting human chorionic gonadotrophin [21]. The cytochrome C biosensor base on the hybrid material consisting of the conducting polymer poly(3-methylthiophene) and MWNTs exhibited a good electrochemical performance concerning direct electron transfer. Moreover, it showed better sensitivity than other structured cytochrome $\mathrm{C}$ biosensors [22].

In this study, the PABA/MWNTs thin films were fabricated by electropolymerization of the composite mixtures prepared from $50 \mathrm{mM}$ 3-aminobenzoic acid (ABA) and various concentrations of MWNTs in $0.5 \mathrm{M} \mathrm{H}_{2} \mathrm{SO}_{4}$. The effect of the concentration of MWNTs on PABA film were demonstrated by cyclic voltammetry and characterized by UV-vis absorption spectra, atomic force microscopy (AFM), and scanning electron microscopy (SEM) techniques.

\section{Experimental}

2.1. Materials. All materials and indium tin oxide- (ITO-) coated glass substrates were purchased from Sigma-Aldrich and used as received. The multiwalled carbon nanotubes (MWNTs) were synthesized by chemical vapor deposition method from Department of Physics and Materials Science, Faculty of Science, Chiang Mai University.

Before electropolymerization, the composite mixtures of $50 \mathrm{mM}$ of $\mathrm{ABA}$ and various concentrations (1.0, 2.5, 5.0, 7.5, 


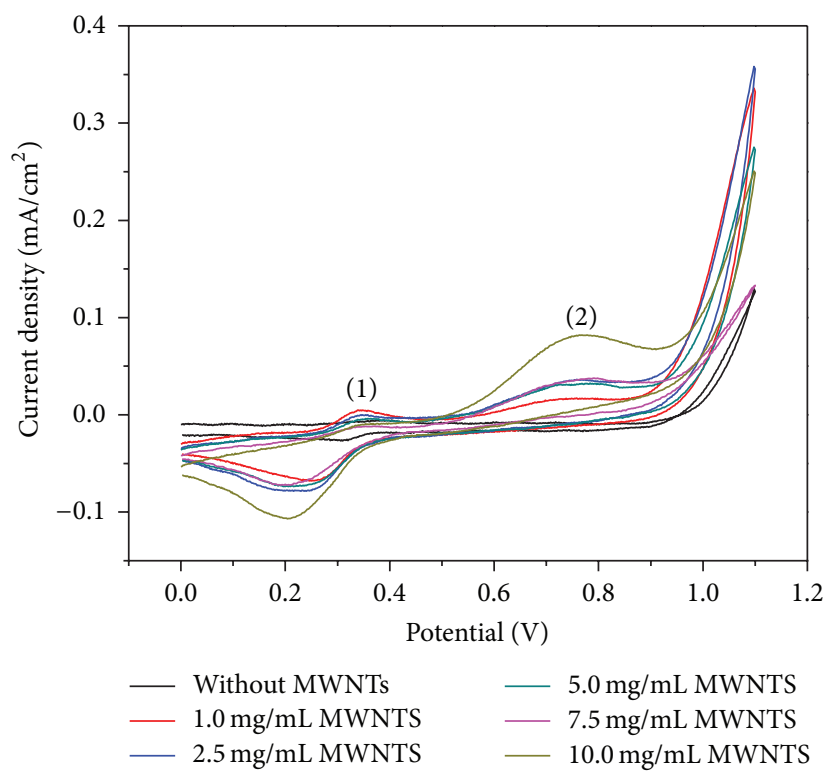

Figure 2: CV traces (selected from the second cycle) during electropolymerization at scan rate of $20 \mathrm{mV} / \mathrm{s}$ of composite mixtures containing $50 \mathrm{mM}$ ABA and $0,1.0,2.5,5.0,7.5$, and $10.0 \mathrm{mg} / \mathrm{mL}$ MWNTs in $0.5 \mathrm{M} \mathrm{H}_{2} \mathrm{SO}_{4}$.

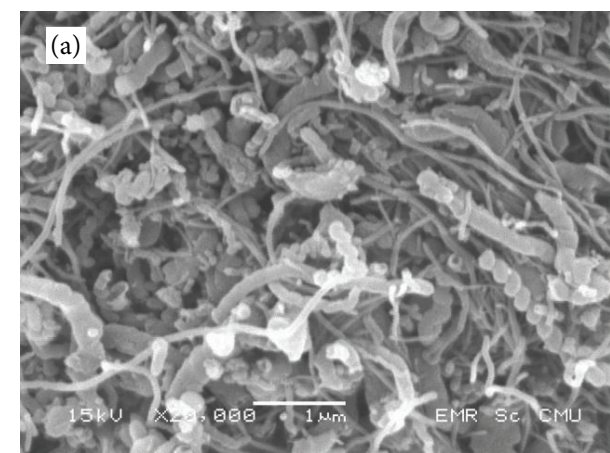

(a)

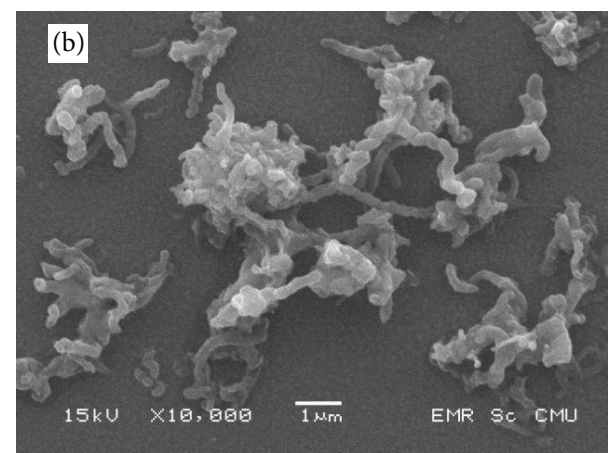

(b)

Figure 3: SEM images of (a) MWNTs and (b) PABA/MWNTs composite thin film containing $7.5 \mathrm{mg} / \mathrm{mL}$ MWNTs after electropolymerization for 5 cycles in $0.5 \mathrm{M} \mathrm{H}_{2} \mathrm{SO}_{4}$.

and $10.0 \mathrm{mg} / \mathrm{mL}$ ) of MWNTs were prepared. The 1.0, 2.5, $5.0,7.5$, and $10.0 \mathrm{mg} / \mathrm{mL}$ of MWNTs were dispersed in a solution of $50 \mathrm{mM} \mathrm{ABA}$ in $0.5 \mathrm{M} \mathrm{H}_{2} \mathrm{SO}_{4}$ by ultrasonication for $30 \mathrm{~min}$. The aggregated MWNTs were then removed by centrifugation at $4000 \mathrm{rpm}$ for $1 \mathrm{~h}$. The dispersed MWNTs in ABA solution (after sonication) and the supernatant solution (after sonication/centrifugation) were studied by UV-vis absorption spectroscopy (Lambda $950 \mathrm{UV}$-vis spectrophotometer). An ITO-coated glass substrate was cleaned in ultrasonic bath before being used in electropolymerization experiment.

2.2. Fabrication of the Composite Thin Films. Electropolymerization processes were performed in 3-electrode setup potentiostat (eDAQ potentiostat ED410 e-corder 410) using platinum wire as counter electrode, $\mathrm{Ag} / \mathrm{AgCl}$ aqueous electrode as reference electrode, and ITO-coated glass substrate as working electrode. The ITO electrode surface area for electropolymerization was $1 \mathrm{~cm}^{2}$. The PABA/MWNTs composite thin films were electropolymerized on the ITO-coated glass slide by switching potential range from 0 to $1100 \mathrm{mV}$ at scan rate of $20 \mathrm{mV} / \mathrm{s}$ for 5 cycles. The composite thin films were washed with $0.5 \mathrm{M} \mathrm{H}_{2} \mathrm{SO}_{4}$ and distilled water, respectively, for several times to wash out the $\mathrm{ABA}$ monomer residue on the ITO electrode surface. The thin films were then stored in desiccator before characterization. The AFM (NanoScope IIIa, Digital Instruments) and SEM (JEOL JEM6335F) measurements were employed to study morphology of the obtained thin films.

\section{Results and Discussion}

The UV-vis absorption spectra of the obtained composite mixtures and thin films are shown in Figure 1. As can be seen in Figure 1(a), for the composite mixture after 


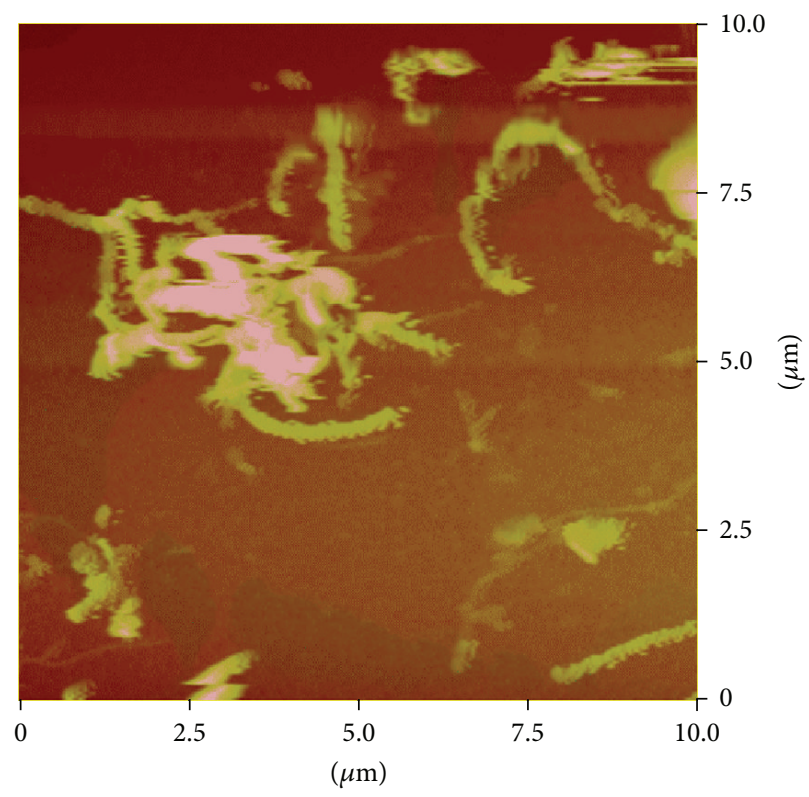

FIGURE 4: AFM image of the PABA/MWNTs composite film containing $7.5 \mathrm{mg} / \mathrm{mL}$ MWNTs after electropolymerization for 5 cycles in $0.5 \mathrm{M} \mathrm{H}_{2} \mathrm{SO}_{4}$.

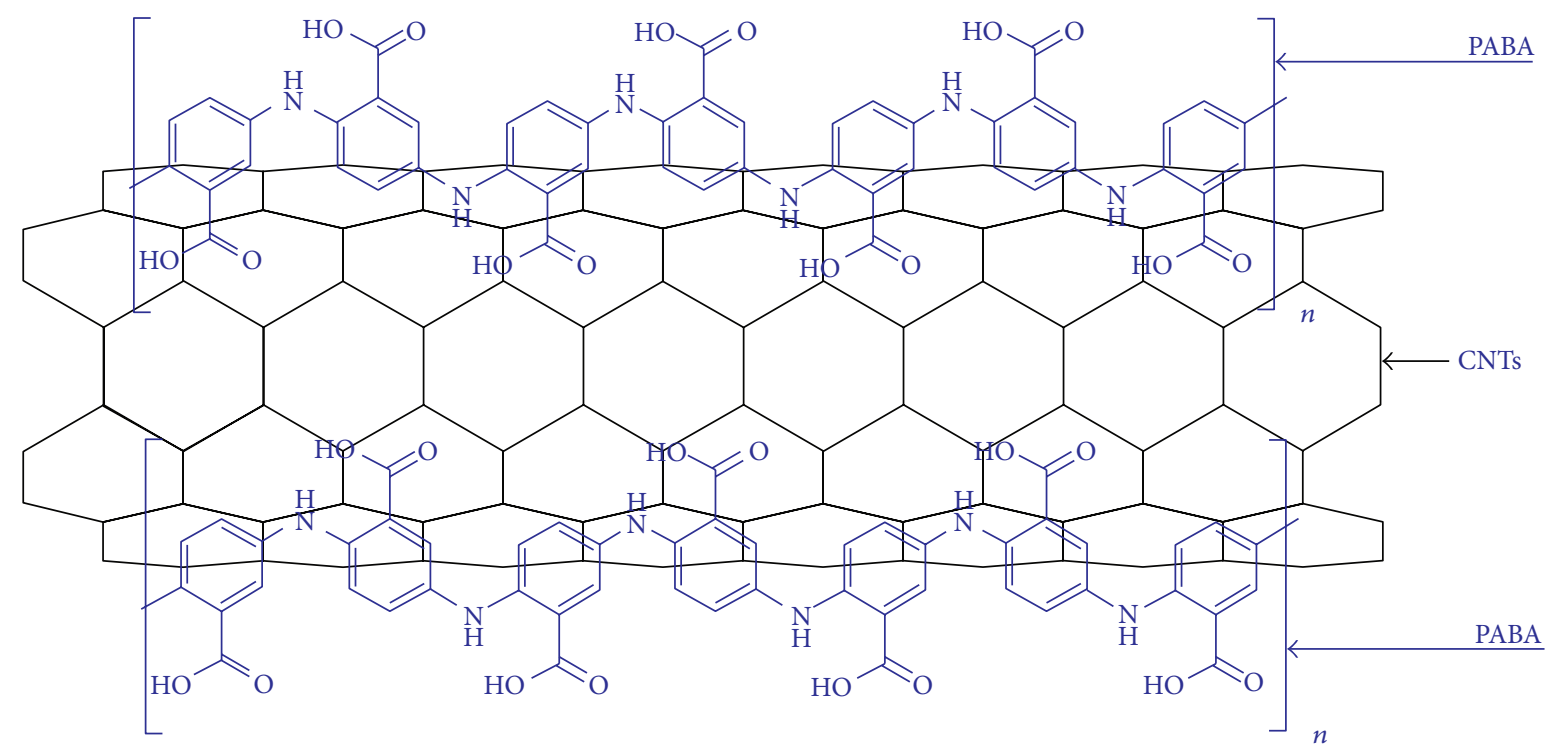

FIGURE 5: Schematic drawing of the proposed noncovalent attachment between PABA and MWNTs of the composite thin film.

sonication, and Figure 1(b), for the composite mixtures after sonication/centrifugation, the absorption peaks were clearly observed at around $295 \mathrm{~nm}$. The baseline of the spectra was found to increase for the mixture after sonication. The different baseline can also be observed for each composite mixture probably due to the aggregated complex bundles of ABA/MWNTs in the mixtures. However, the baselines were decreased for the composite mixture after sonication/centrifugation because the aggregated complex bundles were removed from the composite mixtures [23, 24]. Moreover, the unique baseline can be obtained after centrifugation. We therefore used these mixtures for preparation of the composite thin films. The absorption peaks of the obtained PABA/MWNTs composite films as shown in Figure 1(c) appeared at around $295 \mathrm{~nm}$ in UV region and at around $480 \mathrm{~nm}$ in visible region. The two absorption bands were assigned to $\pi-\pi^{*}$ interband transition associated to the benzoid/quinoid ring structure and $n-\pi^{*}$ transition from the nonbonding nitrogen lone pair to the $\pi^{*}$ conduction band $[23,24]$. Therefore, this indicated that MWNTs did not exhibit the UV-vis absorption peak of both the composite mixture and the PABA/MWNTs composite films. 
To fabricate the PABA/MWNTs composite thin films, electropolymerization of $50 \mathrm{mM}$ ABA monomer solution containing $0,1.0,2.5,5.0,7.5$, and $10.0 \mathrm{mg} / \mathrm{mL}$ of MWNTs in $0.5 \mathrm{M} \mathrm{H}_{2} \mathrm{SO}_{4}$ on ITO-coated glass substrate was performed by cyclic voltammetry (potential range between 0 and $1100 \mathrm{mV}$ at a $20 \mathrm{mV} / \mathrm{s}$ ). Figure 2 shows the $\mathrm{CV}$ traces for electropolymerization of 1 cycle of the composite mixtures of ABA containing various concentrations of MWNTs. The PABA/MWNTs composite thin films were deposited and grown on the ITO-coated glass substrates. The PABA thin film showed one pair redox peak with the anodic current peak at around $0.35 \mathrm{~V}$ and cathodic peak at around $0.2 \mathrm{~V}$. In addition, the PABA/MWNTs composite thin films showed another anodic current peak at about $0.75 \mathrm{~V}$. It can be concluded that this anodic current peak of the composite thin films was probably due to the presence of MWNTs in the thin films. The anodic peak currents of the PABA/MWNTs composite thin films were clearly observed indicating higher electroactivity than PABA thin film. Moreover, MWNTs had larger effective surface area which can increase the amount of PABA loading on the films. Therefore, the pair redox current peaks at $0.75 \mathrm{~V}$ (anodic peak from PABA/MWNTs composite) increased and at $0.2 \mathrm{~V}$ (cathodic peak) decreased whereas the anodic peak at $0.35 \mathrm{~V}$ (from pure PABA) was decreased with increasing of MWNTs concentration. This indicated that the MWNTs affected the oxidation process of the PABA thin film; therefore, MWNTs can enhance the electroactivity of the PABA film.

Moreover, the potential of anodic peak was shifted with increasing concentration of MWNTs. The reason for potential shifting was that the strong adsorption of PABA in MWNTs led to more conjugated structure of PABA [22]. Furthermore, the increase of the current peak indicated that higher concentration of MWNTs, which had large specific surface area, could increase the amount of PABA loading and lead them to have good electron transfer. Therefore, the electron transfer of redox reaction in this work was promoted by the presence of MWNTs.

The surface morphology of the PABA/MWNTs composite thin films was further studied by SEM and AFM techniques. Figure 3(a) shows the surface morphology of MWNTs which have average diameters of about $72 \mathrm{~nm}$. The example of surface morphology of the composite thin film obtained from electropolymerization of the composite mixture containing $7.5 \mathrm{mg} / \mathrm{mL}$ MWNTs was presented in Figure 3(b). As shown in the Figure 3(b), the aggregates of the $\mathrm{PABA} / \mathrm{MWNTs}$ composite formed on the ITO electrode with average diameter of about $226 \mathrm{~nm}$. This can be also previously observed in AFM image as shown in Figure 4.

From the SEM and AFM images in Figures 3 and 4, respectively, we proposed that the presence of MWNTs can lead PABA to wrap around the MWNTs bundles as noncovalent attachment between PABA and MWNTs. The schematic drawing of this proposed structure is shown in Figure 5. This may be the utility to future use as modified electrode in biosensor application.

\section{Conclusion}

In summary, the electropolymerization of PABA/MWNTs composite thin films was successfully fabricated on ITOcoated glass substrate which is also used as working electrode. The presence of MWNTs can enhance the current of redox peaks of the PABA and lead the composite thin films showing good electron transfer. The AFM and SEM images demonstrated the aggregation bundles of MWNTs and PABA on the substrate. We proposed that PABA can wrap around MWNTs. These composite thin films will be investigated in biosensor application in the future work.

\section{Conflict of Interests}

The authors declare that there is no conflict of interests regarding the publication of this paper.

\section{Acknowledgments}

The authors wish to acknowledge the Research Grant for New Scholar (MRG5580133) from the Thailand Research Fund (TRF), the Thailand's Office of the Higher Education Commission (CHE), and Chiang Mai University. The supports from the Thailand's Office of the Higher Education Commission, Rajamangala University of Technology Lanna, and the Graduate School, Chiang Mai University, are also acknowledged.

\section{References}

[1] T. F. Otero and I. Cantero, "Conducting polymers as positive electrodes in rechargeable lithium-ion batteries," Journal of Power Sources, vol. 81-82, pp. 838-841, 1999.

[2] F. M. Kelly, L. Meunier, C. Cochrane, and V. Koncar, "Polyaniline: application as solid state electrochromic in a flexible textile display," Displays, vol. 34, no. 1, pp. 1-7, 2013.

[3] K. K. Krishnani, S. Srinives, B. C. Mohapatra et al., "Hexavalent chromium removal mechanism using conducting polymers," Journal of Hazardous Materials, vol. 252-253, pp. 99-106, 2013.

[4] P. Humpolicek, V. Kasparkova, P. Saha, and J. Stejskal, “Biocompatibility of polyaniline," Synthetic Metals, vol. 162, no. 7-8, pp. 722-727, 2012.

[5] N. K. Guimard, N. Gomez, and C. E. Schmidt, "Conducting polymers in biomedical engineering," Progress in Polymer Science, vol. 32, no. 8-9, pp. 876-921, 2007.

[6] S. Ramakrishnan, "Conducting polymers: from a laboratory curiosity to the market place," Resonance, vol. 2, no. 11, pp. 4458, 1997.

[7] J. L. Bredas and R. Silbey, Conjugated Polymers, Kluwer Academic Publishers, 1991.

[8] F. R. R. Teles and L. P. Fonseca, "Applications of polymers for biomolecule immobilization in electrochemical biosensors," Materials Science and Engineering C, vol. 28, no. 8, pp. 15301543, 2008.

[9] A. Baba, P. Taranekar, R. R. Ponnapati, W. Knoll, and R. C. Advincula, "Electrochemical surface plasmon resonance and waveguide-enhanced glucose biosensing with $\mathrm{N}$-alkylaminated polypyrrole/glucose oxidase multilayers," ACS Applied Materials and Interfaces, vol. 2, no. 8, pp. 2347-2354, 2010. 
[10] A. Baba, T. Mannen, Y. Ohdaira et al., "Detection of adrenaline on poly(3-aminobenzylamine) ultrathin film by electrochemical-surface plasmon resonance spectroscopy," Langmuir, vol. 26, no. 23, pp. 18476-18482, 2010.

[11] A. Benyoucef, F. Huerta, J. L. Vázquez, and E. Morallon, "Synthesis and in situ FTIRS characterization of conducting polymers obtained from aminobenzoic acid isomers at platinum electrodes," European Polymer Journal, vol. 41, no. 4, pp. 843-852, 2005.

[12] A. B. Mattos, T. A. Freitas, L. T. Kubota, and R. F. Dutra, "An oaminobenzoic acid film-based immunoelectrode for detection of the cardiac troponin $\mathrm{T}$ in human serum," Biochemical Engineering Journal, vol. 71, pp. 97-104, 2013.

[13] S. Sriwichai, A. Baba, S. Phanichphant, K. Shinbo, K. Kato, and F. Kaneko, "Electrochemically controlled surface plasmon resonance immunosensor for the detection of human immunoglobulin G on poly(3-aminobenzoic acid) ultrathin films," Sensors and Actuators B: Chemical, vol. 147, no. 1, pp. 322-329, 2010.

[14] A. Preechaworapun, T. A. Ivandini, A. Suzuki, A. Fujishima, O. Chailapakul, and Y. Einaga, "Development of amperometric immunosensor using boron-doped diamond with poly $(o-$ aminobenzoic acid)," Analytical Chemistry, vol. 80, no. 6, pp. 2077-2083, 2008.

[15] Y. Liao, C. Zhang, Y. Zhang et al., "Carbon nanotube/polyaniline composite nanofibers: facile synthesis and chemosensors," Nano Letters, vol. 11, no. 3, pp. 954-959, 2011.

[16] L. Hu, D. S. Hecht, and G. Grüner, "Carbon nanotube thin films: fabrication, properties, and applications," Chemical Reviews, vol. 110, no. 10, pp. 5790-5844, 2010.

[17] D. Olney, L. Fuller, and K. S. V. Santhanam, "A greenhouse gas silicon microchip sensor using a conducting composite with single walled carbon nanotubes," Sensors and Actuators B: Chemical, vol. 191, pp. 545-552, 2014.

[18] G. Xu, B. Li, X. T. Cui, L. Ling, and X. Luo, "Electrodeposited conducting polymer PEDOT doped with pure carbon nanotubes for the detection of dopamine in the presence of ascorbic acid," Sensors and Actuators B: Chemical, vol. 188, pp. 405-410, 2013.

[19] P. D. Tam and N. V. Hieu, "Conducting polymer film-based immunosensors using carbon nanotube/antibodies doped polypyrrole," Applied Surface Science, vol. 257, no. 23, pp. 98179824, 2011.

[20] K. Shen, C. Hu, L. Chang, and K. Ho, "A complementary electrochromic device based on carbon nanotubes/conducting polymers," Solar Energy Materials and Solar Cells, vol. 98, pp. 294-299, 2012.

[21] M. S. Dresselhaus, G. Dresselhaus, and P. Avouris, Carbon Nanotubes: Synthesis, Structure, Properties and Applications, Springer, Berlin, Germany, 2001.

[22] M. Eguilaz, L. Agui, P. Yanez-Sedeno, and J. M. Pingarron, "A biosensor based on cytochrome $\mathrm{C}$ immobilization on poly3methylthiophene/multiwalled carbon nanotubes hybridmodified electrode. Application to the electrochemical determination of nitrite," Journal of Electroanalytical Chemistry, vol. 644, pp. 30-35, 2010.

[23] V. Bavastrello, T. B. C. Terencio, L. Belmonte, P. Cossari, and C. Nicolini, "Influence of substituents in electrochemical and conducting properties of polyaniline derivatives and multi walled carbon nanotubes nanocomposites," Thin Solid Films, vol. 520, no. 18, pp. 5877-5883, 2012.
[24] A. Baba, Y. Kanetsuna, S. Sriwichai et al., "Nanostructured carbon nanotubes/copper phthalocyanine hybrid multilayers prepared using layer-by-layer self-assembly approach," Thin Solid Films, vol. 518, no. 8, pp. 2200-2205, 2010. 

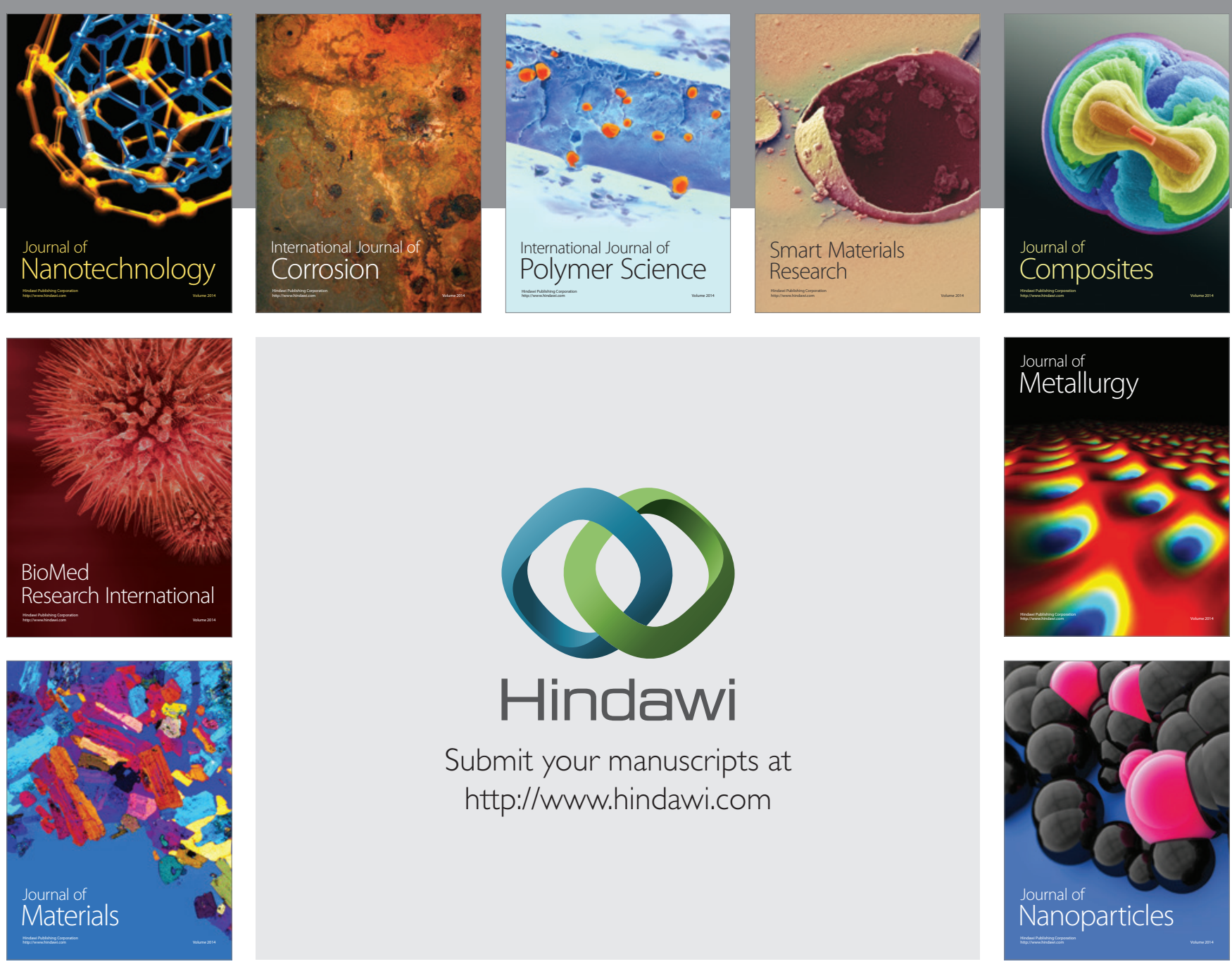

Submit your manuscripts at http://www.hindawi.com
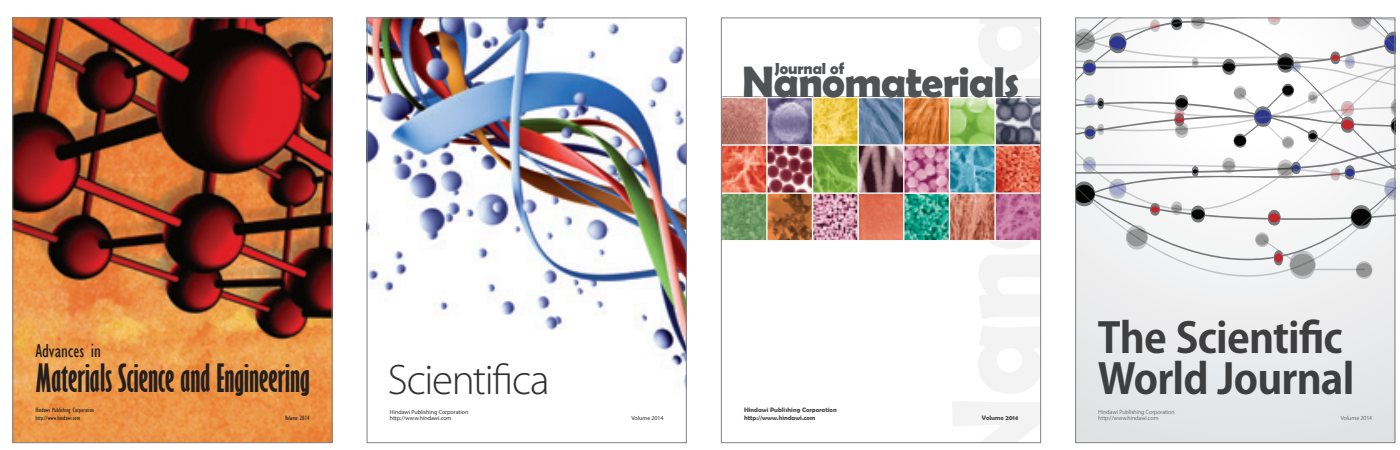

\section{The Scientific World Journal}
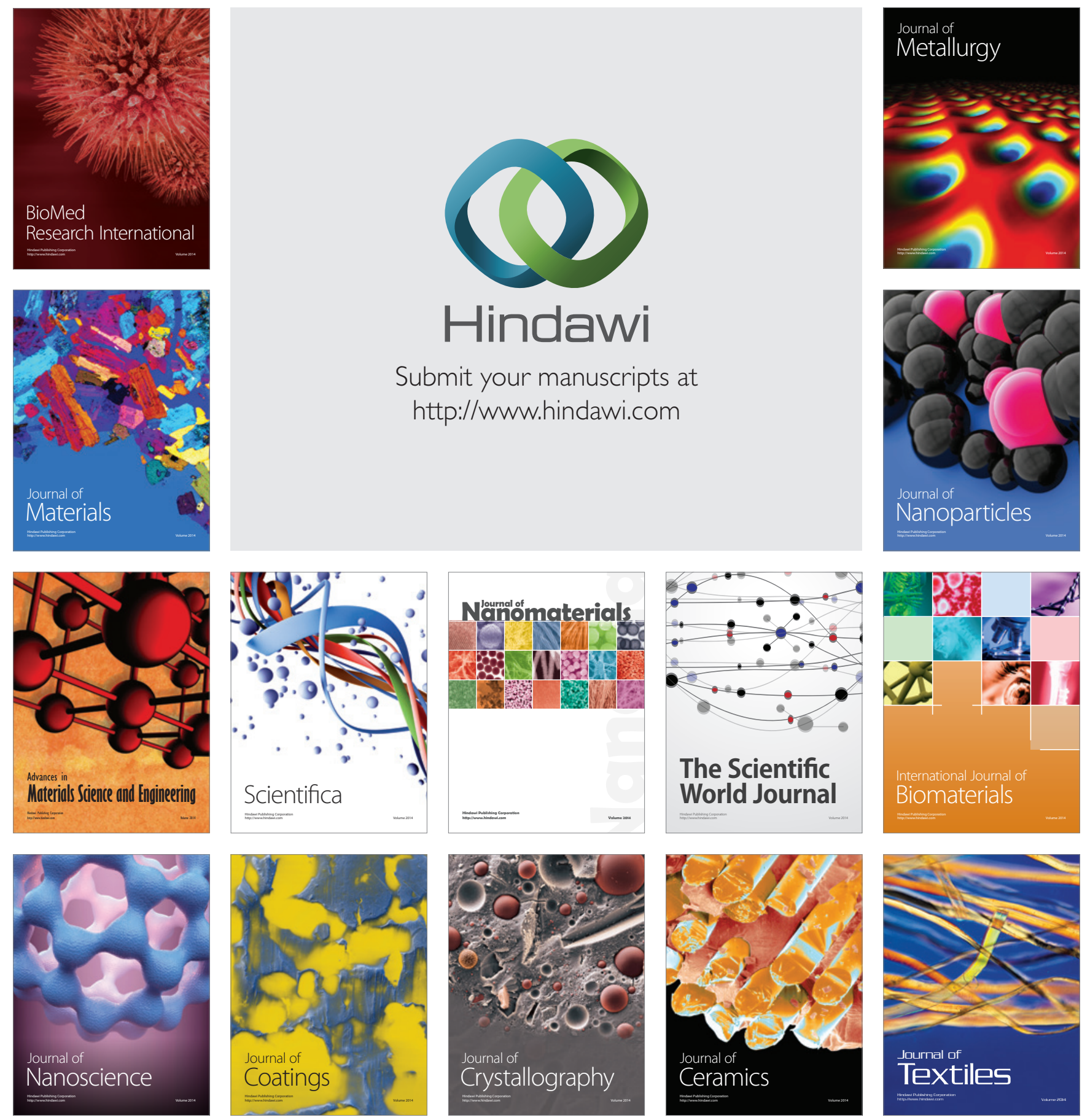